\title{
Ability to detect hypoglycaemic symptoms
}

Hong Kong Med J 2016;22:87

DOI: 10.12809/hkmj154759

To the Editor-I read with interest the excellent article "Avoiding hypoglycaemia: a new target of care for elderly diabetic patients." by Wong in the October 2015 issue of the Hong Kong Medical Journal. ${ }^{1}$ There is one aspect worth mentioning. Electronic sensor systems and trained diabetes-alert dogs can serve as an effective early warning system for elderly people with diabetes. With their acute sense of smell, hypoglycaemia alert dogs are able to detect changes in the chemical composition of their owner's sweat or breath (eg exhaled methyl nitrate, products of ketosis) and can thus smell the low blood sugar. In addition to olfactory changes, the dogs may also respond to changes in the mood of the owner (many diabetics become irritated when their blood sugar drops) or visual signs such as muscle tremor. The dogs alert their owners immediately by nudging, licking, jumping, or barking. ${ }^{2-4}$ Approximately $75 \%$ to $81 \%$ of diabetic patients who have a trained hypoglycaemia alert dog report an improved quality of life. ${ }^{4}$ A recent Italian study that used dogs for cancer detection found that a professionally trained dog could detect prostate cancer with an accuracy of $98 \%$ (volatile organic compounds in urine samples). ${ }^{5}$ Although further research is urgently needed, ${ }^{4}$ a brief indication of the potential effectiveness of trained hypoglycaemia alert dogs should be included in a review article.

Martin Hofmeister *, PhD

Consumer Centre of the German Federal State of Bavaria

Department Food and Nutrition

Mozartstraße 9, D-80336 Munich

Germany

* Corresponding author: hofmeister@vzbayern.de

\section{References}

1. Wong CW. Avoiding hypoglycaemia: a new target of care for elderly diabetic patients. Hong Kong Med J 2015;21:44454 .

2. Hügler S. Diabetic alert dogs: A good nose for hypoglycemia [in German]. Dtsch Med Wochenschr 2012;137:25.

3. Petry NM, Wagner JA, Rash CJ, Hood KK. Perceptions about professionally and non-professionally trained hypoglycemia detection dogs. Diabetes Res Clin Pract 2015;109:389-96.

4. Weber KS, Roden M, Müssig K. Do dogs sense hypoglycaemia? Diabet Med 2015 Oct 27. Epub ahead of print.

5. Taverna G, Tidu L, Grizzi F, et al. Olfactory system of highly trained dogs detects prostate cancer in urine samples. J Urol 2015;193:1382-7. 